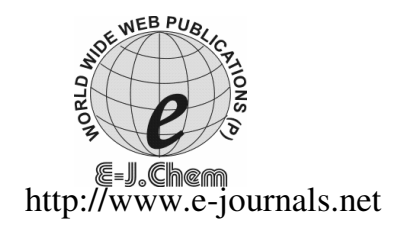

ISSN: 0973-4945; CODEN ECJHAO

E-Journal of Chemistry 2010, 7(1), 239-245

\title{
Copper(II) Extraction from Nitric Acid Solution with 1-Phenyl-3-methyl-4-benzoyl-5-pyrazolone as a Cation Carrier by Liquid Membrane Emulsion
}

\author{
BAHARUDDIN HAMZAH* , NOOR JALALUDDIN, \\ ABDUL WAHID WAHAB and AMBO UPE \\ *Faculty of Teacher Training and Education, \\ Universitas Tadulako Palu, Kampus Bumi Tadulako Tondo, 94223 Palu, Indonesia. \\ Faculty of Mathematics and Natural Science, \\ Universitas Hasanuddin Makassar,Kampus Tamalanrea, 90245 Makassar, Indonesia. \\ hamzahhb@yahoo.com
}

Received 19 March 2009; Accepted 15 May 2009

\begin{abstract}
Copper(II) extraction from nitric acid solution with 1-phenyl-3methyl-4-benzoil-5-pyrazolone (HPMBP) as a cation carrier by liquid membrane emulsion (LME) was investigated. The HPMBP initially was synthesized and the synthesis yield is a yellow crystal with melting point of $87-89^{\circ} \mathrm{C}$. The synthesis efficiency is $72.04 \%$ and generally the spectra of IR, ${ }^{1} \mathrm{H}$ NMR and ${ }^{13} \mathrm{C}$ NMR agree with HPMBP structure. The optimum condition for copper(II) extraction were found as follows: concentration of mixed surfactant (span 80+span 20) was $3 \%$, volume ratio of membrane and internal phase was 1 , concentration of HPMBP was $0.020 \mathrm{M}$, concentration of $\mathrm{HCl}$ was $1 \mathrm{M}$, volume ratio of emulsion and external phase was 0.143 . By using these optimum conditions, $30 \mathrm{~mL}$ of LME can extract $1000 \mathrm{ppm}$ of copper(II) within $210 \mathrm{~mL}$ of nitric acid solution with extraction percentage of $97.97 \%$.
\end{abstract}

Keywords: Copper(II), Extraction, Liquid membrane emulsion, HPMBP.

\section{Introduction}

Although in low concentration, the metals in wastewater cause a serious health and environmental problem. The presence of metals in several industrial wastewater like industry of electroplating, battery, ceramic and tannery is a complex example of pollution. Every year, the using of metal increase and their availability decrease, therefore their recovery from wastewater treatment is clearly important thing that must be care.

Conventional treatment techniques for metal recovery as precipitation and filtration always generate solid wastes that need a continue treatment process. The main problems of this method are redissolution of many precipitates, the addition of a great volume of chemical 
reagent and the generation of an enormous amount of sludge that is not easy to dispose. Solvent extraction for metal recovery is another alternative method, but this method is less efficient and uneconomical because it uses several times extraction and back extraction and it need much more solvent. Separation technique that are still developed until now is liquid membrane emulsion technique. This technique offer high scope and potential due to its characteristics such as easy operation, lesser energy requirement, and high selectivity. Liquid membrane emulsion process has the ability to remove and to selectively concentrate the low metal contents in solution, in a continue and fast process, using a thin liquid membrane that present a great interface area, needing only a very small volume of organic solvent.

LME for metal extraction are made by forming water in oil (W/O) emulsion, stabilized by surfactant, contains carrier in the oil phase and the stripping acid in the internal aqueous receiving phase. This emulsion is then dispersed by mild agitation into a feed phase (external phase) containing the metal to be extracted. After extraction, the loaded emulsion is separated from the feed stream, demulsification yields an oil phase that can be recycled. Electrolysis could subsequently recover the metal concentrated in the receiving phase.

Liquid membrane emulsion technique has been used for separation of phenol, substituted phenol ${ }^{2}$, nitro phenol compound ${ }^{3}$ and toluene/n-heptane ${ }^{4}$ from industrial effluent, extraction of metals ${ }^{5-13}$ and amino acid ${ }^{14,15}$. In medical field, this technique has utilized for separation of toxic compound in blood ${ }^{16}$, and extraction of cephalexin ${ }^{17}$.

A cation carrier was needed in metal extraction process by LME. The cation carriers that usually used are salicylaldoxim ${ }^{18}$, benzoylacetone ${ }^{19}$, diisostearylphosphoric acid ${ }^{20}$, $p$-tert-butylcalixaren ${ }^{21}$, trioctylmethyl ammonium chloride ${ }^{22}$, tri- $n$-octylamin or $\mathrm{TOA}^{23}, d i-2$ ethylhexyl phosphoric acid or HDEHP ${ }^{24-26}, \mathrm{~N}$-alkylcaprolactam ${ }^{27}$, tertieramine ${ }^{28}$, ketoconazol $^{29}$, dinonylnaphthalensulphonate acid $^{30}$, etc. Although these carrier were deeply used in metal extraction by LME technique, however they were used in high concentration up to $20 \%{ }^{31}$. Therefore its less efficient and uneconomical.

The alternative compound that recognized well as an effective carrier is HPMBP. Several researches that used HPMBP as an extractant, for example, extraction behavior of rare earth metal (except promethium and ytrium) with HPMBP was studied ${ }^{32}$. Synthesis of HPMBP and its applied in extraction of copper, zinc, nickel, manganese and iron were investigated ${ }^{33}$. Extraction of $\mathrm{Pu}(\mathrm{IV})$ and $\mathrm{Th}(\mathrm{IV})$ with HPMBP were done ${ }^{34}$. Extraction of lanthanum (III), europium (III) and lutetium (III) into chloroform with fluorinated HPMBP has also been reported ${ }^{35}$.

In this paper, we present a study of copper (II) extraction from acidic nitric solution using HPMBP as a carrier by liquid membrane emulsion technique. We use combining surfactant (span 80+span 20) for emulsion stability, kerosene as the solvent and hydrochloric acid solution as the internal aqueous receiving phase.

\section{Experimental}

1-Phenyl-3-methyl-5-pyrazolone was supplied by P.T. Intraco, benzoyl chloride, copper(II) sulphate, nitric acid, hydrochloric acid, sodium hydroxide, calcium hydroxide, the surfactant (span 80+span 20), and solvents (kerosene, 1,4-dioxane) were obtained from Merck and used directly as received.

\section{Synthesis of HPMBP}

1-Phenyl-3-methyl-5-pyrazolone (15 g) was dissolved in $160 \mathrm{~mL}$ of 1.4-dioxane by heating. Calcium hydroxide $(24 \mathrm{~g})$ was added following by benzoyl chloride $(10 \mathrm{~mL})$ drop wise within 2 minutes. The temperature increased during the first few minutes. The reaction mixture was refluxed for 30 minutes. Calcium complex of the desired compound formed in 
the flask was decomposed by pouring the mixture into dilute hydrochloric acid (200 mL). A yellowish orange precipitate was formed slowly. It was filtered under suction, washed with a little water and 1.4-dioxane and recrystallised.

\section{Emulsion preparation and copper(II) extraction}

Water in oil emulsions were prepared by initially blending the HPMBP and mixed surfactant (span 80+span 20) with kerosene to get the membrane phase. The internal aqueous stripping phase $(\mathrm{HCl})$ was added slowly to the membrane phase with agitation of contents at 2,000 rpm in $10 \mathrm{~min}$.

Certainty volume of emulsion was added into certainty volume of copper(II) solution (500 ppm) and stirred at $300 \mathrm{rpm}$ in 15 minutes. The aqueous external phase was separated and the copper(II) concentration was measured by AAS with wavelength of $324.7 \mathrm{~nm}$.

\section{Determination of experimental optimum condition}

Several important factors which affect the percentage extraction of copper(II) with liquid membrane emulsion are surfactant concentration, HPMBP concentration, volume ratio of the membrane phase to the internal stripping aqueous phase, volume ratio of the emulsion to the external phase, concentration of $\mathrm{HCl}$ in internal stripping aqueous phase and feed concentration. The investigated parameters with their range as follows:

\begin{tabular}{lc}
\hline \multicolumn{1}{c}{ Parameter } & Variation range \\
\hline Surfactant concentration, \% v/v & $1-5$ \\
HPMBP concentration, M & $0.005-0.025$ \\
Volume ratio of membrane phase to internal phase & $0.5-2.0$ \\
Volume ratio of emulsion to external phase & $0.1-0.2$ \\
HCl concentration, M & $0.5-2.0$ \\
Feed concentration, ppm & $400-1800$ \\
\hline
\end{tabular}

\section{Results and Discussion}

\section{Synthesis of HPMBP}

The synthesis yield is a yellow crystal with melting point of $87-89{ }^{\circ} \mathrm{C}$ and synthesis efficiency is $72.04 \%$. From the IR spectra, several band appeared at $3101,3059,1641,1568 \mathrm{~cm}^{-1}$ assigned to $-\mathrm{OH}$ stretching, aromatic $\mathrm{C}-\mathrm{H}$ stretching, aromatic/non aromatic $\mathrm{C}=\mathrm{O}, \mathrm{C}=\mathrm{N}$ stretching, respectively. In ${ }^{1} \mathrm{H}$ NMR spectra, several peaks appeared at chemical shift of 2.00 , $7.30,7.46,7.50,7.58,7.64,7.89$ and $13.00 \mathrm{ppm}$, with total proton abundance of 14 . Whereas, the ${ }^{13} \mathrm{C}$ NMR spectra showed some peaks in chemical shift of 15.9, 103.4, 126.7, $137.3,120.8,127.9,131.9,137.6,128.4,129.2,148.0,161.6$ and 191.9, with total carbon abundance of 17 . The IR, ${ }^{1} \mathrm{H}$ NMR and ${ }^{13} \mathrm{C}$ NMR spectra agree with the HPMBP structure.

\section{Effect of surfactant concentration}

In emulsion liquid membrane system, a surfactant is added as an emulsifier in the liquid membrane phase affects not only the stability of the liquid membrane but also the swelling of the emulsion and the rate of metal extraction. Figure 1 shows the effect of surfactant concentration to the extraction percentage of copper(II). It was observed that, when the surfactant concentration was $1 \%$, there was severe membrane rupture. Although the emulsion was expected to be stabilized with increasing surfactant concentration, the degree of stability becomes relatively constant due to the saturation of surfactants at the oil-water interface and it makes the extraction percentage of $\mathrm{Cu}(\mathrm{II})$ is also relatively constant. It is known that the increase of surfactant concentration does not favor extraction kinetics. Because of that, the amount of surfactant in the membrane must be minimal, but it must be enough to stabilize the emulsion. The optimum surfactant concentration ( $\operatorname{span} 80+$ span 20 ) was taken as $3 \%(\mathrm{v} / \mathrm{v})$. 


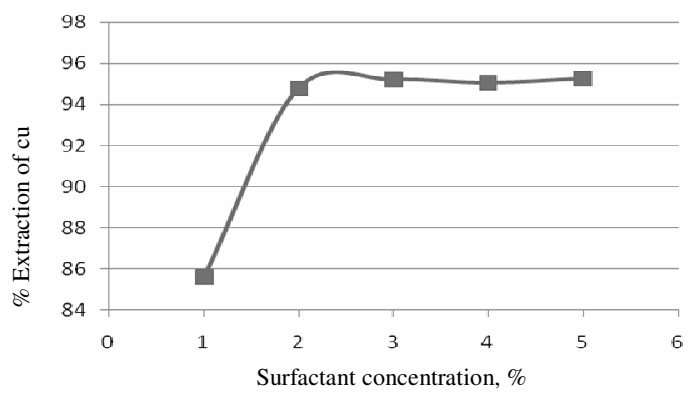

Figure 1. Effect of surfactant concentration to extraction percentage of $\mathrm{Cu}(\mathrm{II})$.

\section{Effect of HPMBP concentration}

Increasing the amount of carrier (HPMBP) has two effects. First, the viscosity of membrane phase, which limits the extraction rate, decreases on increasing the carrier concentration. Second, hence the carrier acts as a thinner for the membrane phase and enhances the rate of solute transport through membrane for extraction. At the same time, increasing the carrier concentration over a certain limit decreases the stability of the emulsion. A very high concentration of carrier in the membrane does not result in a benefit due to the increase in viscosity, which leads to larger globules. On the other hand, the increase in the concentration of the carrier also promotes the permeation swelling, which dilutes the internal phase and decreases the extraction percentage of copper(II). The optimum extraction percentage of copper(II) is found at a carrier concentration of $0.02 \mathrm{M}$ based on emulsion phase as shown in Figure 2.

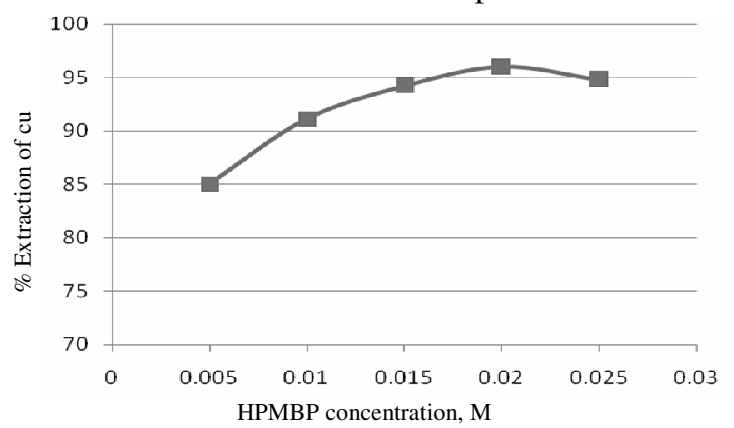

Figure 2. Effect of HPMBP concentration to extraction percentage of $\mathrm{Cu}(\mathrm{II})$.

\section{Effect of the volume ratio of membrane phase/internal phase}

The volume ratio of the membrane phase to the internal phase were varied between 0.5 - 2 . It is evident that the increase of volume ratio of the membrane phase to the internal phase leads to an increase in the stability of the emulsion. The results may be explained on the basis that increasing the internal phase volume makes the emulsion unstable and leads to a leakage of the internal phase into the external phase.

From Figure 3, it is observed that the extraction percentage of copper(II) increases slightly with the increasing of the $\mathrm{Vm} / \mathrm{Vi}$ ratio from 0.5 to 1 , because the ejection of the internal phase is easier when its proportion in the emulsion is higher. It is also observed that the extraction percentage of copper(II) decreases with the increasing of the $\mathrm{Vm} / \mathrm{Vi}$ of 2.0. This result can be explained that the decreasing of internal phase volume makes the decreasing of the capability of the internal phase in receiving the copper(II). Therefore, it seems that the optimum volume ratio of membrane phase to the internal phase is 1 . 


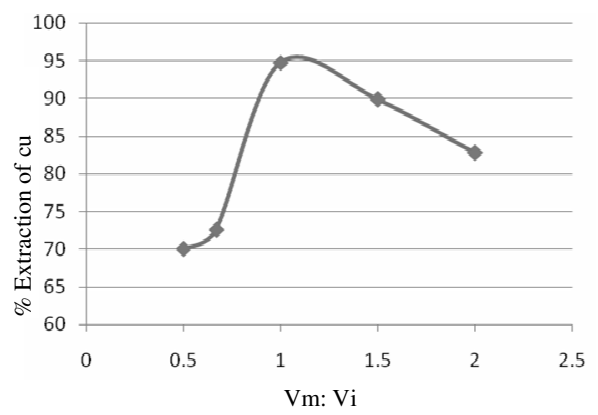

Figure 3. Effect of volume ratio $\mathrm{Vm}: \mathrm{Vi}$ to extraction percentage of $\mathrm{Cu}(\mathrm{II})$.

\section{Effect of the volume ratio of the emulsion/external phase}

The volume ratio of the emulsion to external phase varied between 0.111 and 2.00. Figure 4 shows the effect of variation of this ratio on extraction percentage of copper(II). It is evident that the increase of volume ratio of the emulsion to the external phase leads to an increase in the rate constant of metal extraction. The increase of volume ratio of the emulsion to the external phase from 0.143 leads to an increase of the emulsion coagulation. Indeed, with increasing the volume ratio, the swelling phenomenon becomes remarkable, fast and accompanied by a more significant coalescence of the internal droplets that grow. Therefore, it seems that the optimum volume ratio of the emulsion to the external phase is 0.143 .

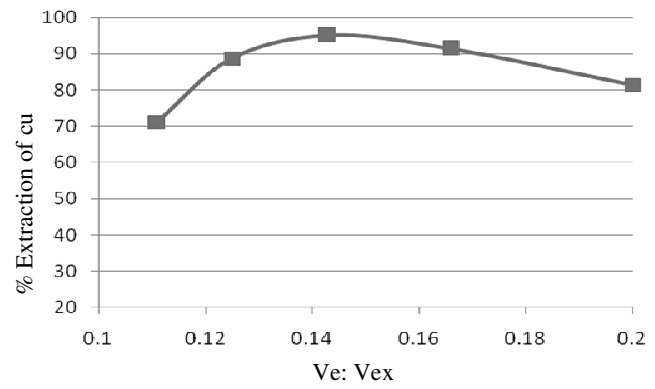

Figure 4. Effect of volume ratio $\mathrm{Ve}: \mathrm{Vex}$ to extraction percentage of $\mathrm{Cu}(\mathrm{II})$.

\section{Effect of $\mathrm{HCl}$ concentration in internal phase}

The extraction reaction of copper(II) occurs at the external/membrane interface with the HPMBP, the complex being formed according to the following equation.

$$
2 \mathrm{HPMBP}_{(\mathrm{org})}+\mathrm{Cu}^{2+}{ }_{(\mathrm{aq})} \longleftrightarrow \mathrm{Cu}(\mathrm{PMBP})_{2(\mathrm{org})}+2 \mathrm{H}^{+}{ }_{(\text {(a) }}
$$

$\mathrm{Cu}(\mathrm{PMBP})_{2}$ species are highly soluble in the membrane (organic) phase and diffuse towards the internal/membrane interface. At this interface, the $\mathrm{Cu}(\mathrm{PMBP})_{2}$ complex is contacted with strongly acidic hydrochloric solution, which regenerates the HPMBP to its acid form and releases the $\mathrm{Cu}(\mathrm{II})$ in the internal phase, according to the following back extraction reaction.

$$
\mathrm{Cu}(\mathrm{PMBP})_{2(\text { org })}+2 \mathrm{H}^{+}{ }_{(\mathrm{aq})} \longleftrightarrow 2 \mathrm{HPMBP}_{(\mathrm{org})}+\mathrm{Cu}^{2+}{ }_{(\text {aq })}
$$

Figure 5 presents the effect of hydrochloric acid concentration on the extraction percentage of copper(II). It was observed that the extraction percentage of copper(II) is increased by increasing the acidity in the stripping phase (internal phase). The differences hydrogen ion chemical potentials between the two aqueous phases (external phase and 
internal phase) are the main driving force in the emulsion liquid membrane process. Thus, the extraction percentage of copper(II) increases gradually with increasing the concentration of hydrochloric acid from 0.5 to $1 \mathrm{M}$, this owing to the increase of the capacity of receiving phase (internal phase). However, for a concentration of hydrochloric acid greater than $1 \mathrm{M}$, the emulsion swells up due to osmosis, which leads to the dilution of the internal phase, causing a less effective stripping. Another reason, it may be due to the reaction of the acid with the surfactant which results in a partial loss of its surfactant properties that causing unstable emulsion. Therefore, it is concluded that the optimum $\mathrm{HCl}$ concentration is $1 \mathrm{M}$.

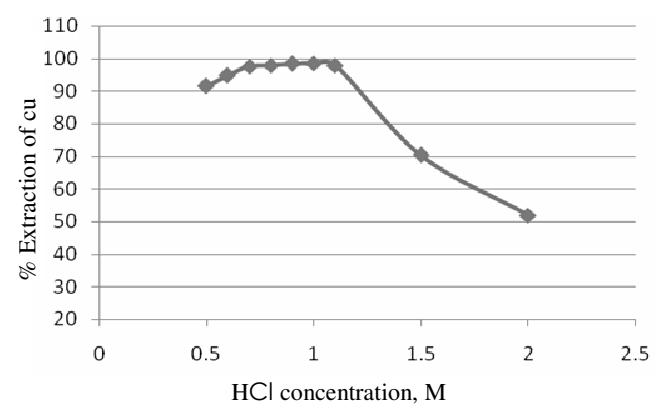

Figure 5. Effect of $\mathrm{HCl}$ concentration to extraction percentage of $\mathrm{Cu}(\mathrm{II})$.

\section{Effect of feed concentration of copper(II) in external phase}

The effect of feed concentration on extraction percentage of copper(II) at optimum conditions is shown in Figure 6. By using $30 \mathrm{~mL}$ emulsion, it is observed that the increase in feed concentration from 400 to $1800 \mathrm{ppm}$, the extraction percentage of copper(II) is relatively constant. However, the increase of feed concentration higher than $1000 \mathrm{ppm}$, the extraction percentage is decrease. We concluded that the capacity of receiving phase is limited.

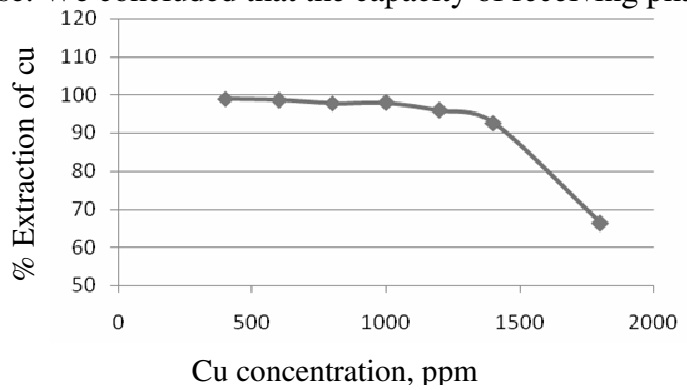

Figure 6. Effect of feed concentration of $\mathrm{Cu}($ (II) to extraction percentage of $\mathrm{Cu}$ (II).

\section{Conclusions}

The synthesis yield is a yellow crystal with melting point of $86-87^{\circ} \mathrm{C}$ and synthesis efficiency is $72.04 \%$. Generally the spectra of IR, H-NMR and C-NMR agree with HPMBP structure.

The optimum condition for copper(II) extraction were found as follows: concentration of mixed surfactant ( $\operatorname{span} 80$ +span 20) was 3\%, volume ratio of membrane phase and internal phase was 1, concentration of HPMBP was $0.020 \mathrm{M}$, concentration of $\mathrm{HCl}$ was $1 \mathrm{M}$, volume ratio of emulsion phase and external phase was 0.143 . By using these optimum conditions, $30 \mathrm{~mL}$ of liquid membrane emulsion can extract $1000 \mathrm{ppm}$ of copper(II) within $210 \mathrm{~mL}$ of nitric acid solution with extraction percentage of $97.97 \%$. 


\section{References}

1. Cahn R P and Li N N, New Development in Separation Methods. Marcel Dekker Inc., New York, 1976, 13-27.

2. Park Y, Skelland A H P, Forney L J and Kim J H, Water Res., 2006, 40, 1763-1772.

3. Luan J and Plaisicr A, J Membr Sci., 2004, 229, 235-239.

4. Chakraborty $\mathrm{M}$ and Bart H J, Colloids and Surfaces A: Physicochemical and Engineering Aspects, 2006, 272, 15-21.

5. Boyadzhiev L and Lazarova Z, Chem Eng Sci., 1987, 42(5), 1131-1135.

6. Raghuraman B, Tirmizi N and Wiencek J, AIChE J., 1993, 39, 39-46.

7. Raghuraman B, Tirmizi N and Wiencek J, Environ Sci Technol., 1994, 28, 1090-1102.

8. Kasaini H, Nakashio F and Goto M, J Membr Sci., 1998, 146, 159-168.

10. Uddin M S and Kathiresan M, Separ Purif Tech., 2000, 19, 3-9.

11. Chakravarti A K, Chowdhury S B and Mukherjee D C, Colloids and Surfaces A: Physiochemical and Engineering Aspects, 2000, 166(1), 7-25.

12. Saravanan S, Begum K M M S and Anantharaman N, Journal of the University of Chemical Technology and Metallurgy, 2006, 41(3), 333-342.

13. Valenzuela F, Araneda C, Vargas F, Basualto C and Sapag J, Chemical Engineering Research and Design, 2009, 87(1), 102-108.

14. Bhuvaneswari S, Begum K M M S, Sivashanmugam P and Anantharaman N, $J$ Scietific and Industrial Research, 2003, 62, 329-333.

15. Venkatesan S, Begum K M M S, Sivashanmugam $\mathrm{P}$ and Anantharaman N, J Indian Chem Soc., 2004, 81, 1- 3.

16. Li N N, Hydrometallurgy, 1983, 9, 277-305.

17. Sahoo G C and Dutta N N, J Membr Sci., 1998, 145, 15-26.

18. Gurel L, Altas L and Buyukgungor H, Environ Eng Sci., 2005, 22(4), 411-420.

19. Noviandri I, Thesis, Magister of Science, Bandung Institute of Technology, Indonesia, 1992.

20. Kondo K and Matsumoto M, Separ Purif Tech., 1998, 13, 109-115.

21. Ye Z F, Wang Y P, Liu Y S, Jiang Z I., Shen X, Zhu I G and Shi X F, J Membr Sci., 1999, 163, 367-372.

22. Park W, Kim G W, Kim S S and Sohn I J, Sep Sci Technol., 2001, 36(10), 2309-2326.

23. Kozlowski C, Apostoluk W, Walkowiak W and Kita A, Physiochemical Problems of Mineral Processing, 2002, 36, 115-122.

24. Bourenane S, Samar M E H and Abbaci A, Acta Chim Slov., 2003, 50, 663-675.

25. Basualto C, Poblete M, Marchese J, Ochoa A, Acosta A, Sapag J and Valenzuela F, J Braz Chem Soc., 2006, 17(7), 1347-1354.

26. Sabry R, Hafez A, Khedr M. and Hassanin A E, Desalination, 2007, 212(1-3), 165-175.

27. Yang L, Zhang Z, Guo Y, Gao X and Takeuchi H, Separ Purif Tech., 2005, 47, 88-94.

28. Kozlowski C and Walkowiak W, J Membr Sci., 2005, 266(1-2), 143-150.

29. Farhadi K and Shamsipur M, Anal Sci., 2005, 21, 501-505.

30. Gawronski R and Religa P, J Membr Sci., 2007, 289(1-2), 187-190.

31. Chiha M, Samar M H and Hamdaoui O, Desalination, 2006, 194, 69-80.

32. Roy A. and Nag K, J Inorganic Nucl Chem., 1978, 40, 331-334.

33. Ivanova E, Anal Chem., 1987, 288, 62.

34. Jia Jun-Mao Fu L and Yude C, J Radio Nucl Chem., 1988, 131, 54-63.

35. Saleh M I, Ahmad M and Darus H, Talanta, 1990, 37, 757-759. 


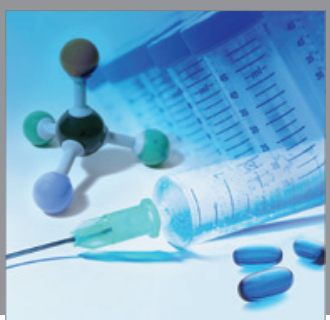

International Journal of

Medicinal Chemistry

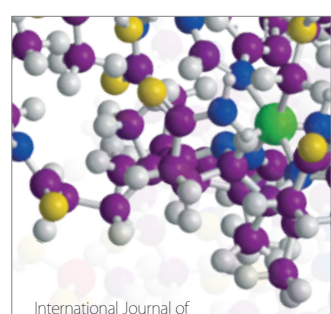

Carbohydrate Chemistry

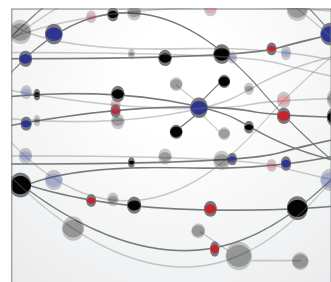

The Scientific World Journal
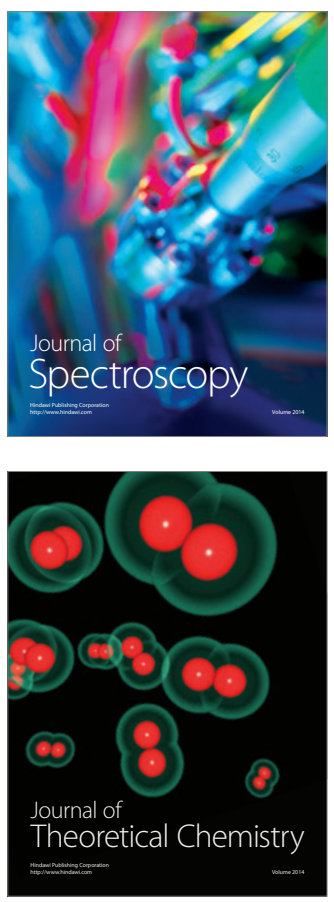
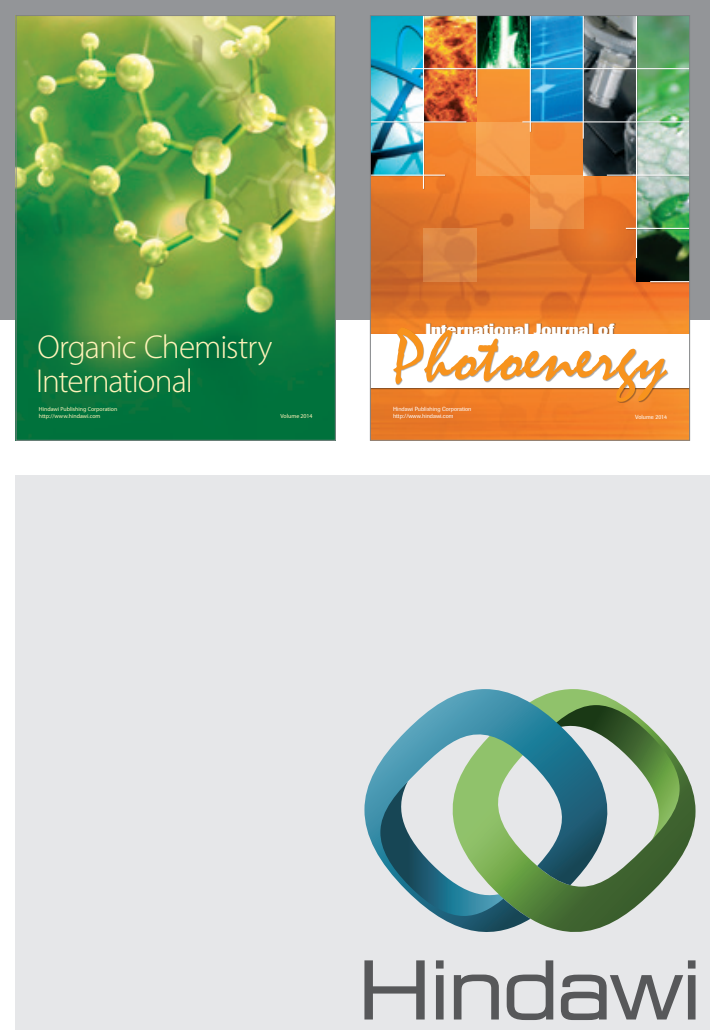

Submit your manuscripts at

http://www.hindawi.com
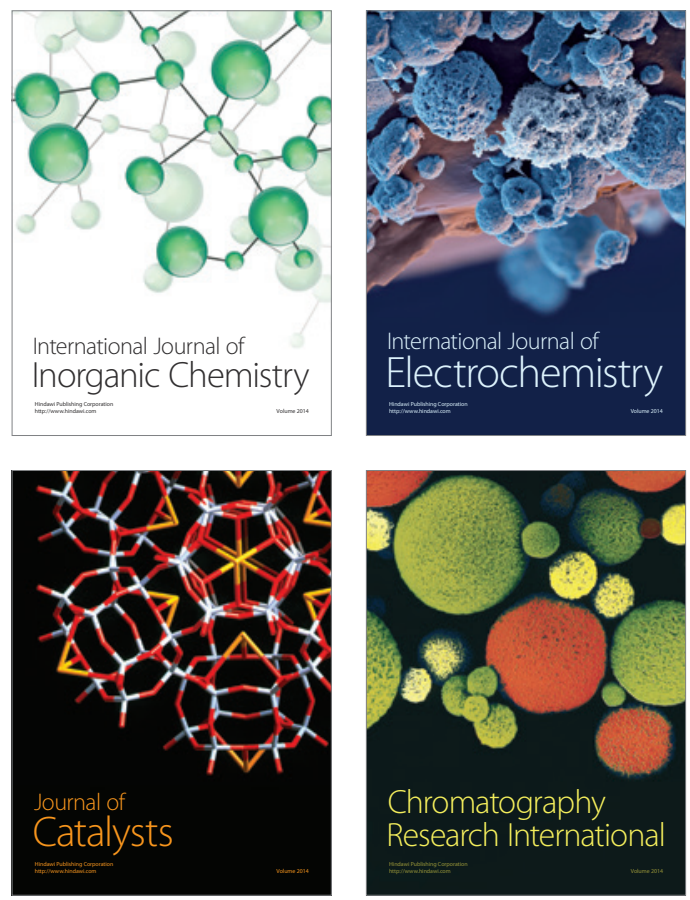
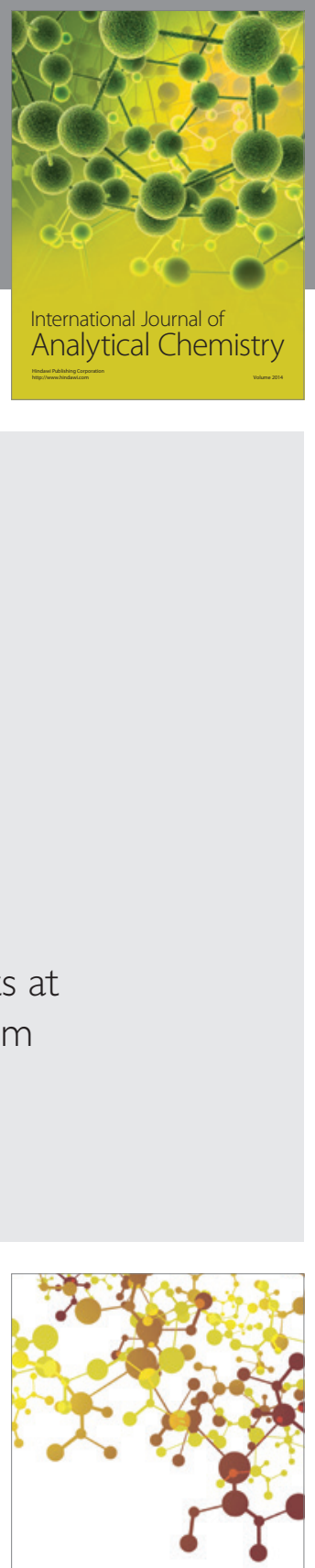

Journal of

Applied Chemistry
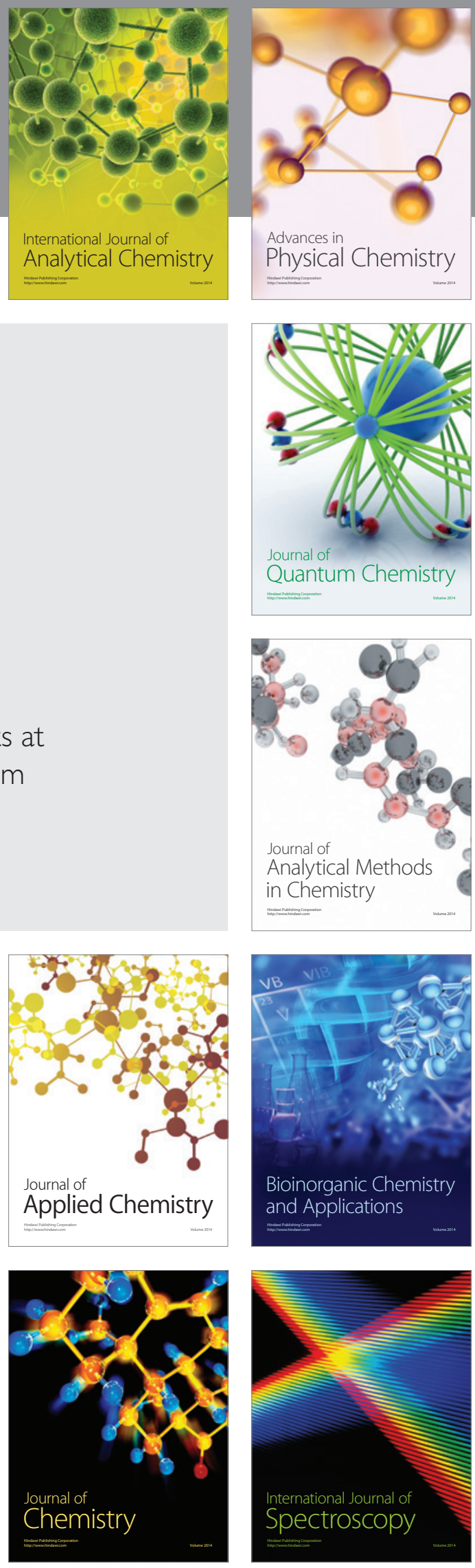